\title{
science \\ Science Editing is indexed in the Scopus
}

\author{
Kihong Kim \\ Department of Energy Systems Research and Department of Physics, Ajou University, Suwon, Korea
}

In the previous issue, I announced that Science Editing began to be indexed in the Emerging Sources Citation Index. In this issue, I am very happy to inform our readers that Science Editing is now being indexed in the Scopus. In the last year, the Content Selection \& Advisory Board of the Scopus informed us that it advised to include Science Editing to the Scopus database. Specifically, it acknowledged the good quality of our contents and considered its potential for growth in submissions and citations highly. I think it is a wonderful achievement considering that the journal is only four years old. I am very grateful to the editorial board members and to the authors who contributed valuable articles to Science Editing. Being indexed in the international databases such as the Scopus and the Emerging Sources Citation Index is very important because it will lead to a substantial increase of submissions of high quality manuscripts. I hope our readers continue to support Science Editing and strongly encourage editors, publishers, authors and reviewers all over the world to contribute their valuable manuscripts to Science Editing, thereby participating in developing it as a world class journal in the field of editing and publishing.

\section{Conflict of Interest}

No potential conflict of interest relevant to this article was reported. 